\title{
Trichoptera from the Great Falls and Turkey Run units of the George Washington Memorial Parkway, Fairfax Co., Virginia, USA
}

\author{
OLIVER S. FLINT, JR.
}

Department of Entomology, National Museum of Natural History, Washington, DC 20013-7012 USA

E-mail: FLINTO@si.edu

\begin{abstract}
A 3-year effort to collect and identify caddisflies (Trichoptera) along 2 sections of the Potomac River was undertaken at the request of the National Park Service. A variety of techniques including Malaise traps, light traps, and hand netting resulted in the collection of 105 species belonging to 17 families and 38 genera. Fifty-seven species or $54 \%$ were deemed rare, 20 species or $19 \%$ were common and 28 species or $27 \%$ were abundant. Comments are made on 7 species of special interest. An addendum lists 6 additional species collected during the 4th year's survey.
\end{abstract}

Key words: Trichoptera, caddisflies, Great Falls, Turkey Run

\section{Introduction}

In 2005 the park naturalist, Brent W. Steury of the George Washington Memorial Parkway, National Park Service, approached the entomologists at the National Museum of Natural History with a proposal to provide funding for a 3-year survey of various insect groups at certain sections of the Parkway. Five of us agreed to survey for our research groups along 2 sections of the Parkway, viz. Great Falls (GF) and Turkey Run (TR).

The Parkway lies on the southwestern rim of the Potomac River in northern Virginia and runs for 25 miles $(40 \mathrm{~km}$ ) between the Beltway (the highway that encircles Washington at a radius of about $16 \mathrm{~km}$ ) at the western end and Mt. Vernon, George Washington's home, at the southern end. Four and a half air miles $(7.2 \mathrm{~km}$ ) beyond the western end of the Parkway lies Great Falls Park, also administered by the same agency. The Parkway follows a sharp escarpment, known as the Palisades, along the southern side of the river west from Washington, with Great Falls and the Mather Gorge just downriver, marking the western end of the canyon the river has cut through the bedrock.

\section{Methods and materials}

Collections were made using a variety of methods: Malaise traps, light traps, ultraviolet light at a sheet, and hand netting. Specimens taken in the Malaise traps went directly into alcohol, but those collected by the other methods were killed dry with "excess" numbers being put into alcohol.

Three Townes-style Malaise traps (Townes 1962) were operated at each park unit, for 2006 only from May 4 until November 9, but for longer periods in 2007 (13 March-28 November), and 2008 
(13 March-17 November). Two of the traps at Turkey Run were placed at, or close to (and twice inundated during floods) the riverside each year. The 3rd trap was placed, for 2 years, at the edge of the forest far from the river, but it still collected caddis. This trap on the 3rd year was moved close to the river and placed directly over a small, first order streamlet. Two of the Great Falls traps at were placed in the "Swamp" for the first 2 years, one where the soil was wet or rarely flooded, the other at a drier situation. One of these was moved the last year to where the soil was even wetter or rarely shallowly flooded. The 2nd swamp trap was moved the last year and placed over the small stream that drains the swamp near the "Quarry" site. The 3rd trap was operated at the edge of the "Quarry" all years, and placed under small trees, at the edge of an open field.

In addition to the Malaise traps, battery operated Universal Black Light Traps (BioQuip \#2851) were set at various sites, 17 times each at TR and at GF. Hand net collections were made at both areas, 19 times at TR and 20 times at GF. One collection was made at TR with a UV illuminated sheet and hand picking, while 5 such collections were made at GF. Individuals of interest were selected and pinned while fresh from these collections, with excess numbers then placed into alcohol.

Identifications were made later in the laboratory using standard references. In case of doubt, genitalia would be cleared in warm $\mathrm{KOH}$ and then stored with the specimen. Generally all examples were sexed, counted and records kept electronically. On some occasions when large numbers of a common species were taken, an estimate only was made of the numbers. No attempt was made to identify females of the Hydropsyche scalaris group, as their specific identification is not readily possible.

\section{Results}

After 3 years work we had records for 105 species. In comparison, 358 species are known from Virginia (Flint, Hoffman \& Parker 2004, 2008, 2009): the Park's fauna is thus slightly over 29\% of the whole state fauna. These are placed in 16 families and 38 genera. Great Falls contained 95 species and Turkey Run 76, with 66 species known from both sites.

These results may be compared with those of a 2-day "Bioblitz" of the same area in June of 2006 which resulted in 42 species of caddisflies, 1 of which, Oecetis ditissa, was taken in the "Bioblitz" but not recovered in our large survey (Evans 2008).

An attempt was made to determine relative abundance of the various species. Three categories were established: rare=up to 5 specimens/site/year, common=up to 25 specimens/site/year, and abundant $=$ more that 25 . On these criteria, 57 species or $54 \%$ were deemed rare, 20 species or $19 \%$ were common and 28 species or $27 \%$ were abundant.

There are a number of records of special interest when considering the fauna of Virginia. The first verified Virginian examples of Ceraclea resurgens (Walker) were taken at both GF and TR in May of 2007. Only the 2nd state records of Ceraclea uvalo Ross and Setodes guttatus (Banks) were made at GF. Several species of Polycentropus were of considerable interest. A thriving colony of $P$. carlsoni Morse, the first known in the state, was found at TR in a small, lateral stream that often dries in summer, and a single, distinctive female of an unknown species of Polycentropus was taken at GF. Neophylax mitchelli Carpenter was found at the same small stream as P. carlsoni. This species is common at high elevations in the western part of the state, but otherwise unknown in the lower Piedmont. Finally, an undescribed species of Neophylax was common in the river here. It is also known from several other larger rivers in the lower Piedmont of Virginia. 
In Table 1, the families, genera, and species are arranged alphabetically. For each species, the number of examples taken are given for each year and each site. After the species name is shown the range of months the species was taken and whether it is classified as rare (R), common (C), or abundant (A).

TABLE 1. List of species, flight periods and number of examples found in Townes traps at Turkey Run and Great Falls in 2006-2008.

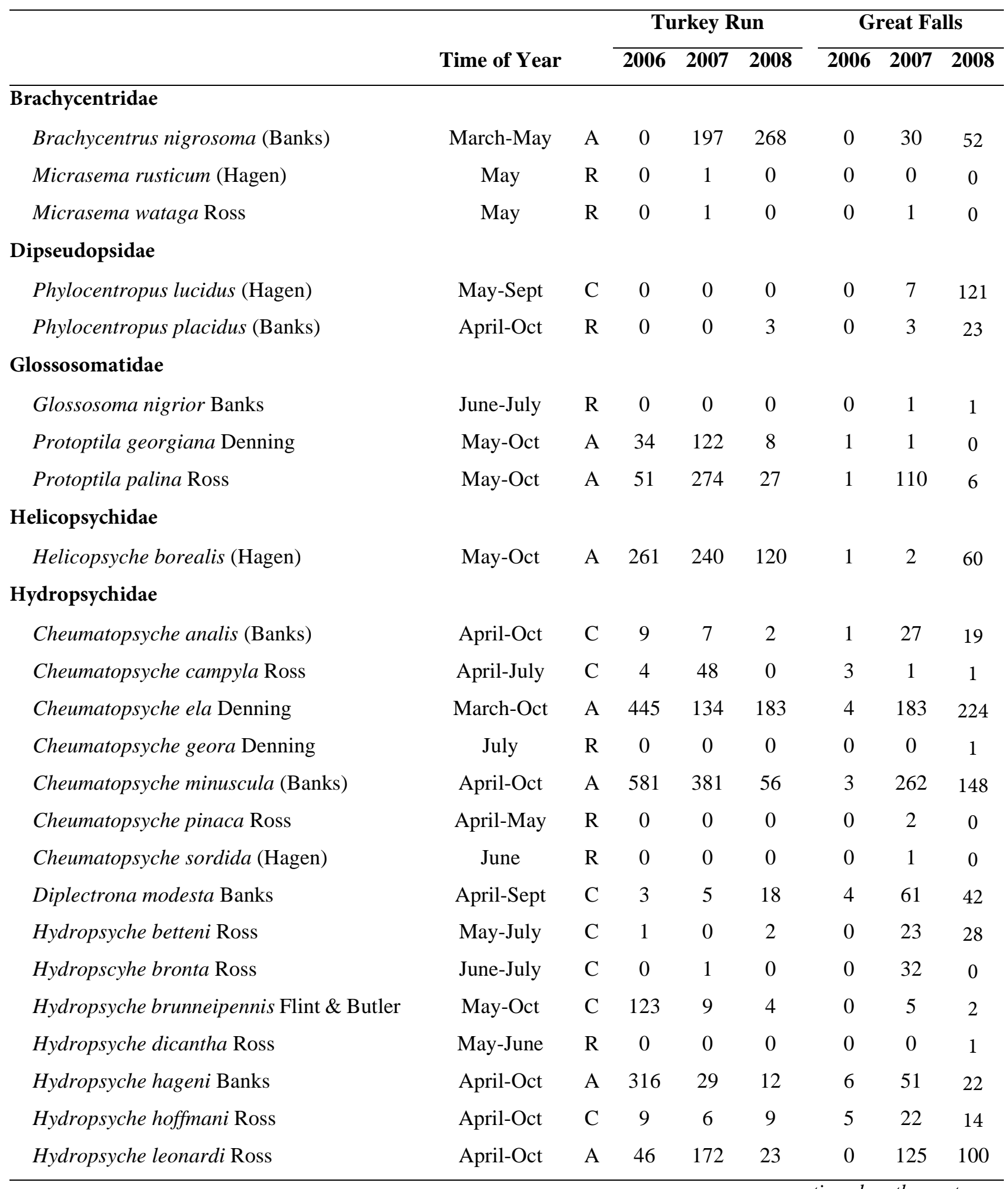


TABLE 1 (continued)

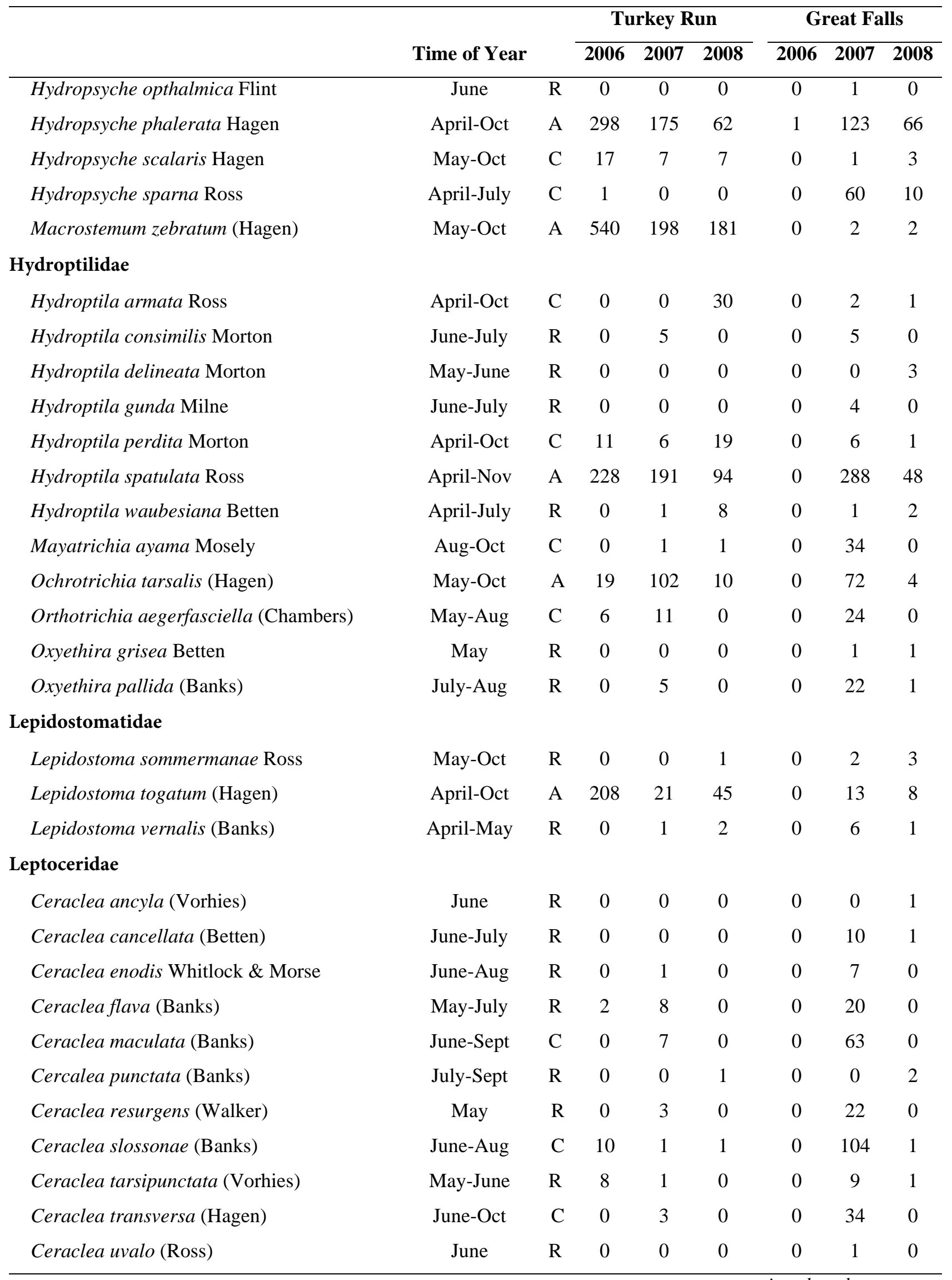


TABLE 1 (continued)

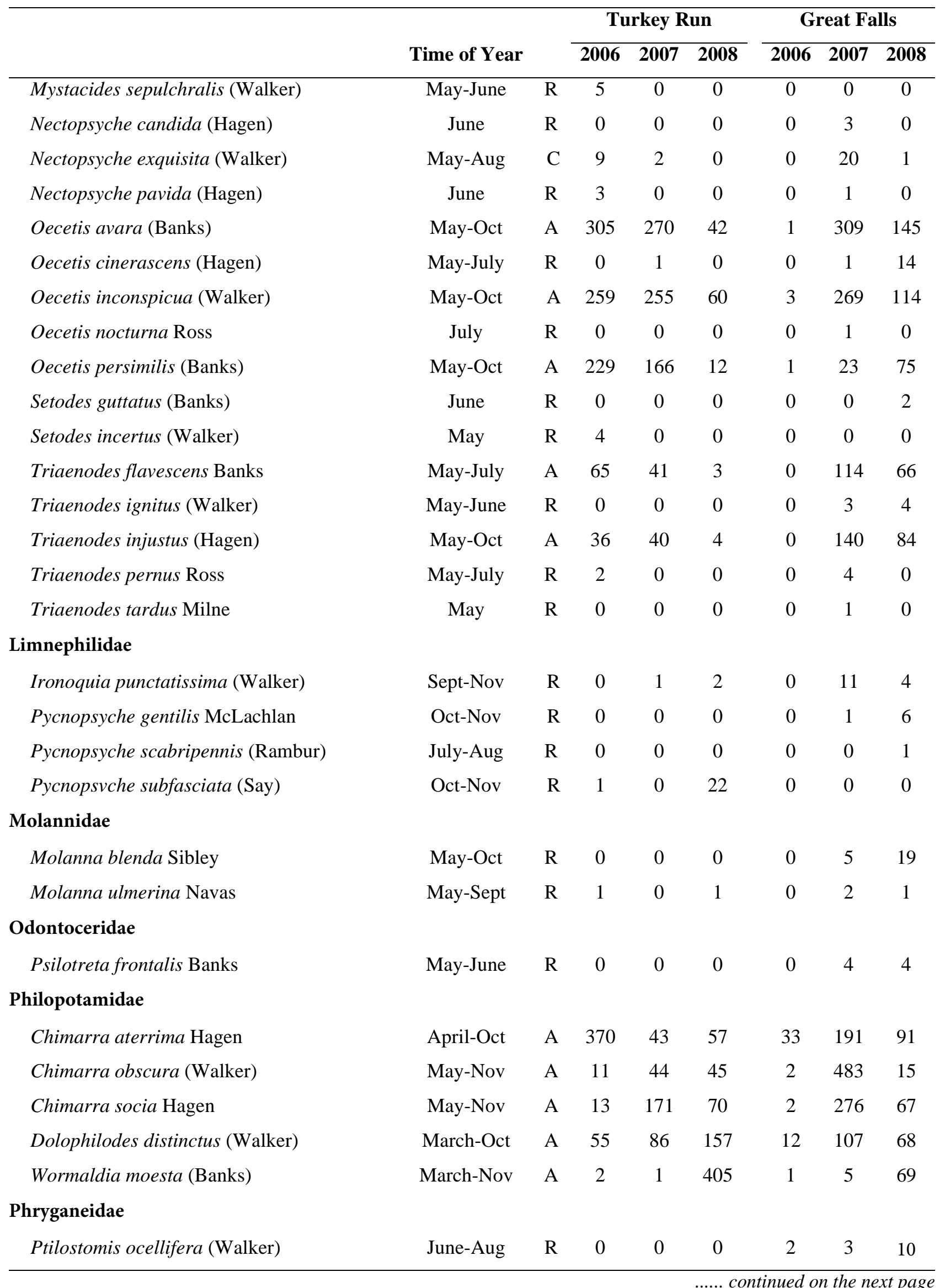


TABLE 1 (continued)

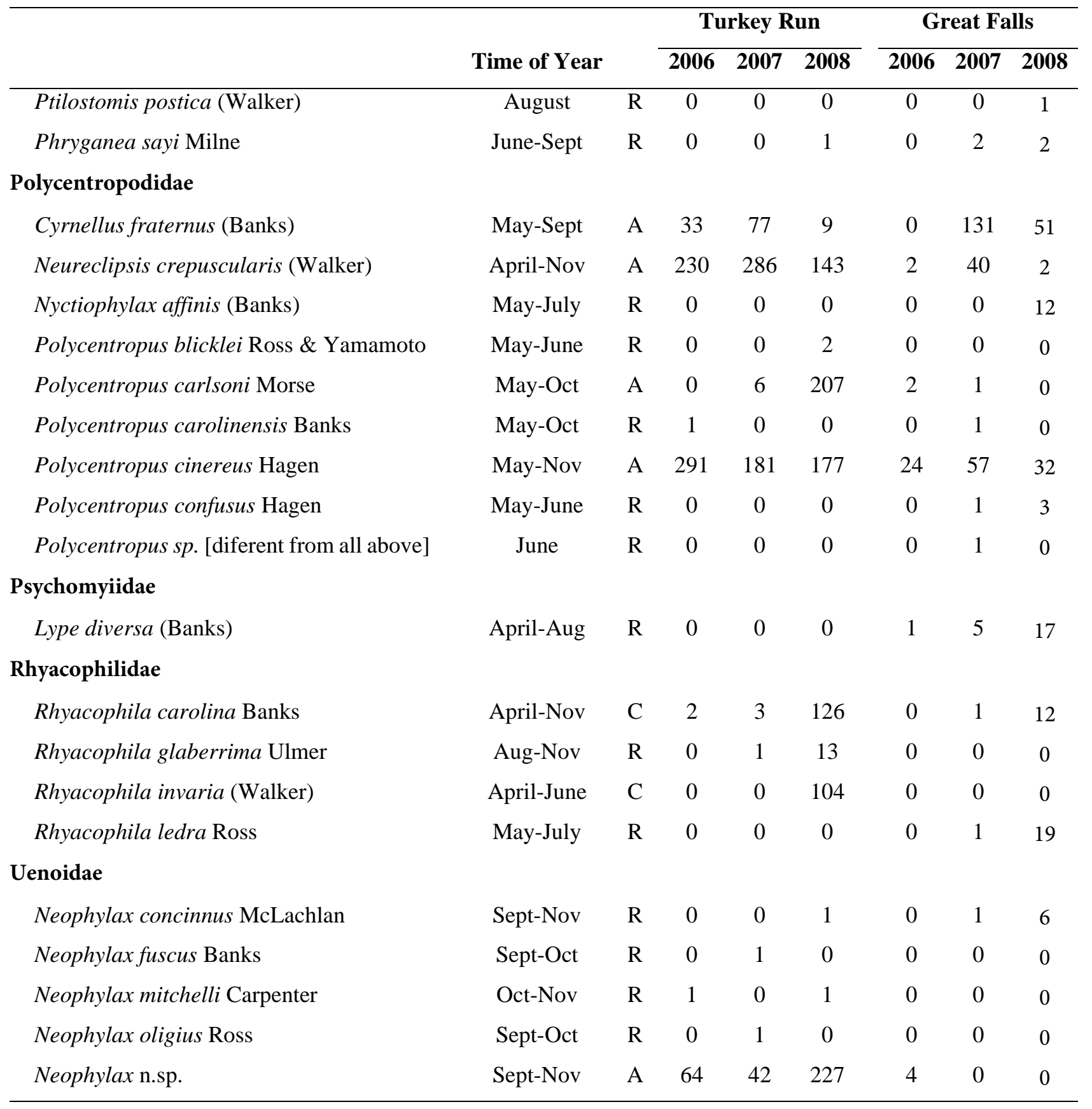

\section{Acknowledgements}

I am most grateful to Brent W. Steury, Supervisory Biologist, George Washington Memorial Parkway, for permits, support of the grant proposal, and other courtesies during this study. Dr. David R. Smith, Systematic Entomology Laboratory, U.S. Department of Agriculture operated the Malaise traps and picked out the caddisflies from the miscellaneous catch for 3 years, Dr. John W. Brown also of the U.S. Department of Agriculture operated and selected caddisflies from his light traps over the 3 years. Dr. Wayne N. Mathis of the Department of Entomology, Smithsonian Institution, netted many caddisflies while sweeping for Ephydridae, Diptera. I am extremely grateful to all. 


\section{References}

Evans, A.V. (2008) The 2006 Potomac Gorge Bioblitz. Banisteria, 32, 3-80.

Flint, O.S., Hoffman, R.L. \& Parker, C.R. (2004) An annotated list of the caddisflies (Trichoptera) of Virginia: Part I. Introduction and families of Annulipalpia and Spicipalpia. Banisteria, 24, 23-46.

Flint, O.S., Hoffman, R.L. \& Parker, C.R. (2008) An annotated list of the caddisflies (Trichoptera) of Virginia: Part II. Families of Integripalpia. Banisteria, 31, 3-23.

Flint, O.S., Hoffman, R.L. \& Parker, C.R. (2009) An annotated list of the caddisflies (Trichoptera) of Virginia: Part III. Emendations and biogeography. Banisteria, 34, 3-16.

Townes, H. (1962) Design for a Malaise trap. Proceedings of the Entomological Society of Washington, 64, 253-262.

\section{Addendum}

Since the meetings in Poland, the 6 Malaise traps have been in operation through July 2009, most at or near the usual sites, and light trap collections made. However 1 Malaise trap was moved from Swamp Run to Mine Run, at GF. This trap has collected 2 more species new to the park: Nyctiophylax denningi Morse and Polycentropus elarus Ross. An additional 4 species have been taken either in the Malaise traps or in the light traps: Hydropsyche slossonae Banks, Hydroptila hamata Morton and Ithytrichia clavata Morton at TR, and Limnephilus submonilifer at both GF and TR. Thus the total number of species now stands at 111 for the park, 98 from GF and 80 from TR with 67 taken at both sites. 